\title{
Network in Promoting Health Literacy: A Case Study of a School under the Local Administration in Thailand
}

\author{
Pennee Kantavong $^{1}$, Chokchai Yuenyong ${ }^{2} \&$ Nuchwana Luengangool $^{2}$ \\ ${ }^{1}$ College of Local Administration, Khon Kaen University, Khon Kaen, Thailand \\ ${ }^{2}$ Faculty of Education, Khon Kaen University, Khon Kaen, Thailand \\ Correspondence: Pennee Kantavong, College of Local Administration, Khon Kaen University, Khon Kaen, \\ Thailand. Tel: 66-89-715-8245. E-mail: pennee@kku.ac.th
}

Received: April 9, $2014 \quad$ Accepted: August 19, $2014 \quad$ Online Published: October 30, 2014
$\begin{aligned} & \text { doi:10.5539/ass.v10n21p19 } \quad \text { URL: http://dx.doi.org/10.5539/ass.v10n21p19 }\end{aligned}$

\begin{abstract}
This research aims to lay a foundation in health literacy for well-informed and inquiring citizens through school and community networks. A municipal school in Phon district, Khon Kaen province in Thailand was recruited as a case study. The research was a participatory action research. Participants were students, school teachers, administrator, the Mayor of the city, district public health officers, police officers, and parents. Two networks were established; a strategic network and a procedure network. The strategic network was centered on the outside organizations, namely the municipality office, district public health office, police station, community organizations, and parents. The procedure network was the collaborative work between higher education institute and school. The two networks also worked collaboratively in order to enhance the promotion of health literacy in the school. The research instruments included field notes, teachers' portfolio and lesson plans, interviewing data, and a record of After Action Reflection. The two-year programme revealed that: 1) teachers showed strong commitment to the continuous promotion of health literacy in school; 2) participating organizations turned out to be a permanent network with school, and; 3) the concept of health literacy extended throughout the community, from students to their families. The parents and community members showed an awareness and interest in promoting health literacy practices.
\end{abstract}

Keywords: health literacy, network, school

\section{Introduction}

\subsection{Health Literacy Development}

The World Health Organization (WHO) defines health literacy (HL) as representing the cognitive and social skills which determine the motivation and individuals to access to understand meaning of good health and capable to use it effectively (Nutbeam, 1998). HL may benefit both personally and socially and has profound implications for education and communication methods. Ratzan (2001), cited in Pearson and Saunder (2009) pointed out that various definitions have been put forward that acknowledge the ability to access, interpret and make decision about information from many sources that promote good health. Nutbeam (2000) stated that HL methods of education provide challenges to communicate in ways that invite interaction, participation, and critical analysis. This approach seems to be in line with critical thinking education. The outcomes of HL could be considered at three levels. Firstly, functional HL aims to improve knowledge of health risks. Functional literacy is for developing effective skills in reading and writing to be able to function effectively in everyday situations, which is compatible with the narrow definition of HL. Secondly, interactive HL focuses on the development of personal skills in a supportive environment. The approach aims to improve personal capacity to act independently based on knowledge received. Communicative or interactive literacy covers more advanced cognitive and literacy skills, which integrate with social skills. These skills can be used to actively participate in everyday activities as well as to apply new information to changing circumstances. Finally, critical HL reflects the cognitive and skills development outcomes. This level would be directed towards improving individual and community capacity in social and economic determinants of health. Critical literacy covers more advanced cognitive skills when this skill integrates with social skills. It can be applied to critically analyze information and to use this information to greater control over life situations. All these various levels of literacy would lead to greater autonomy and personal empowerment (Nutbeam, 2000). 
"Education for health directed towards interactive and critical HL is not new, and has formed part of social mobilization programs for many years" (Nutbeam, 2000, p. 265).

UNESCO has been promoting functional literacy for more than four decades. But when globalization expands rapidly, the result is that world citizens face a prevalence of epidemics and other health problems. The common illnesses found include heart disease, diabetes, and hypertension. Many countries face an increasing fiscal budget percentage for health care. The WHO started a campaign for the better understanding of healthcare under the concept of HL (WHO, 1998). HL "implies the achievement of a level of knowledge, personal skill and confidence to take action to improve personal and community health by changing personal life styles and living conditions" (Nutbeam, 2008).

The early stage of the HL campaign was conducted by health personnel. So the movements have been within a small circle of participants. There were numbers of studies that pointed out that $\mathrm{Hl}$ cannot be left for the health personnel alone. There should be activities in which the participants are various parties, especially the educational system (Institute of Medicine, 2004).

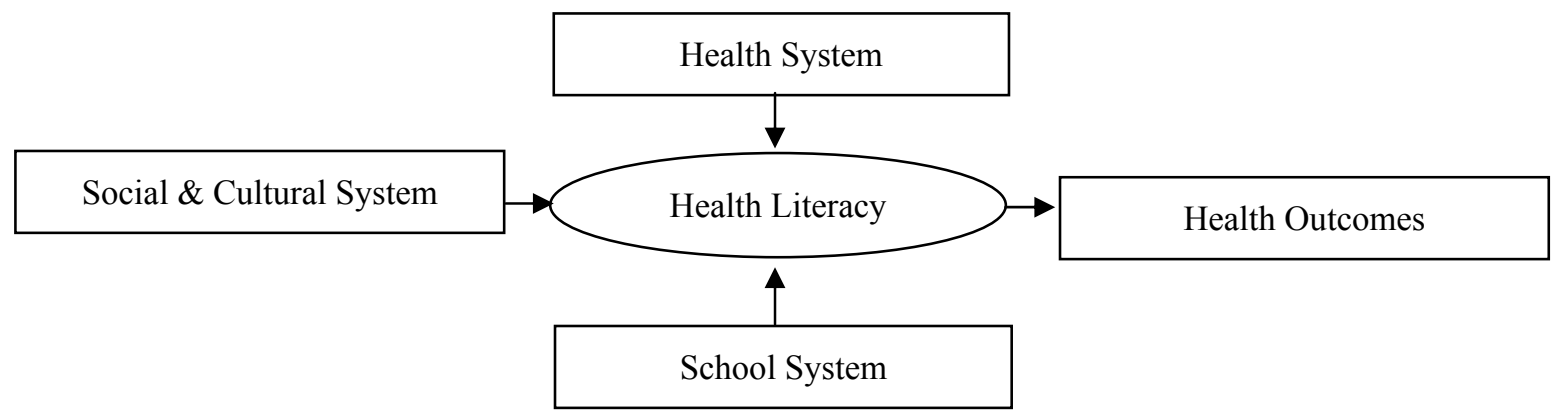

Figure 1. Components and outcome of Health Literacy

Source: Institute of Medicine, 2004

Figure 1 shows the three main components for HL development. The Health System promotes people's health; the School System develops basic essential knowledge and skills for people, and; the Cultural and Social System supports the development of the first two systems. HL is a shared function of social and individual factors. Individual's HL skills and capacities are mediated by their education, culture, and language. Healthy People (2010) pointed out that HL must be recognized at a broad societal level. Each stakeholder group needs to engage in skill building to address both supply side (e.g. those who create health message, information, forms; and those who staff the healthcare and health education system) and the demand side (e.g. clients, the families and care givers, and consumers). Thus, we should engage community organizations and lay public in HL effort (Healthy People, 2010). The outcome of the movement would lead to healthier people and the decreased spending on individual health care. That would lead to a decline of the country's health care spending.

\subsection{Health Promotion in School to Enable the Achievement of Health Literacy}

HL is a new concept in Thailand. The research team learned from the development of the projects in North America and Australia. These countries promoted HL in mid-1980s (St. Leger, 2001). In the first stage of the project implementation, it was found that HL in school was mainly based on content of education and not HL. The students were in good health only when they were in school. So the implementation strategy was modified to be the "Coordinated School Health Program." This program had several essential features:

- Various parties working together in students' HL development. It was no longer left for the physical education and health education teams.

- The teaching and learning in every subject was connected to HL.

- The development project moved through networking between schools and other community organizations.

By the 1990's, a new framework for school health (coordinated school health) was implemented in many countries. The practice went beyond curriculum. They considered the school environment for both social and physical, school-based health policies, connections to health services, and setting network with the local community (St. Leger, 2001). This new approach would lead to the enhancement of students' sustainable HL where they could bring knowledge and skills to apply to their lives with a sense of empowerment. At the same 
time, the project also connected children's learning in HL to their families and the community (Mark, Hudson, Deal, Pateman, \& Middleton; St. Leger, 2001). In order to improve HL, it requires the collaboration between health and education organizations in every level. It also requires a clear understanding between organizations at the very local level (St. Leger \& Nutbeam, 2000). St. Leger (2001) reviewed the reports and meta-analysis which have been published in the last part of the decade about the effectiveness of school health and its outcomes found that the programs need to "focus on cognitive and social outcomes in conjunction with behavior change within an educational framework; ... be relevant to young people's social and cognitive development; be adequately resourced; provide significant professional development for teachers; be holistic on addressing strategic combinations of the curriculum, school physical environment, the school's social environment, partnership with parents and local community and school policies; be based on effective learning theories; and recognize the limitations and opportunities of schools in bringing about substantial health improvements" (p. 6). Ma-Oon (2009) identified psychological characteristics factors related to health promotion and diseases prevention behaviors found that psychological characteristics; knowledge about health promotion, attitude towards health promotion, future orientation and self control, and belief in health promotion and diseases prevention behaviors are predictive variables for health promotion and diseases prevention of students.

Based on concepts from previous research, it was revealed that HL is a promising project for the development of health and learning performance. The knowledge and skills from HL would help both children and parents sustain healthy lives. The Ministry of Public Health foresees the outcome of HL projects in schools, so it promotes the implementation of the project in schools in various parts of Thailand. Khon Kaen province is one of the provinces with rapid growth. However, there are both positive and negative impacts to society. The preparation of people to cope with the rapid change in society cannot keep up with the changes. The educational system seems to be a prime mechanism for development of the people. School and community networks may allow stakeholders to support promoting HL in school in order to provide critical and constructive citizens.

\section{Methodology}

The research was a participatory action research. Participants were students, school teachers, administrator, the Mayor of the city, district public health officers, police officers, and parents. Two networks were established: a strategic network and a procedure network. The strategic network was centered on the outside organizations, namely the municipality office, district public health office, police station, community organizations, and parents The procedure network was the collaborative work between higher education institute and school. The two networks also worked collaboratively in order to enhance the promotion of $\mathrm{HL}$ in the school.

\subsection{Objectives of This Research}

This is a participatory action research aims to 1) to lay foundation for critical and construction citizens by raising an wariness in HL among youth and their families; 2) establish an educational sharing network in order to collaborate in HL promotion; 3) obtain lessons learned from the implementation of HL based on educational sharing networks, and; 4) present policy implementation strategies for involved organizations.

\subsection{Scope of Study}

This study presents a case of HL network development in Sri Muang Phon School, under Phon municipality, Thailand. The school functions as an opportunity expansion school providing education from kindergarten to Grade 9. The participants included 30 school teachers, students from Grade 1 to 9, parents and other family members, a deputy mayor, personnel from the public health center, police officers, and a school administrator.

\subsection{Indicator for Project Achievement}

After two years of project implementation, the outcomes of the project can be judged based on the following indicators.

Table 1. Indicator for project achievement

\begin{tabular}{ll}
\hline Developed indicators & Target groups \\
\hline Students with HL behaviors based on the HL school (Nutbeam, 2008) & Students \\
Teachers' awareness, knowledge, and understanding of HL & Teachers and Teachers' network \\
School and community network plans & - Sri Muang Phon Municipality Schools \\
& - Organizations in community \\
& - Parents \\
\hline
\end{tabular}




\subsection{Research Instruments}

The field note was used as a main tool for data collection. The teacher lesson plans based on HL approach were also considered as evidence for research outcome. The framework for After Action Project meeting was used for monitoring the project.

\subsection{Data Collection}

The data was obtained from observation, interview and collaborative meeting, focus group discussion, teachers' network presentation (oral presentation along with their instructional planning templates) and After Action Reflection.

The research procedure is as follows:

2.5.1 Strategic planning for HL in school. The research team contacted the school and organized the meetings in order to seek for core teachers. These teachers worked as coordinators between both strategic and procedure networks.

2.5.2 Researchers' skills development. Since this is Participatory Action Research, the research team provided training sessions and close monitoring for a core teachers' team so they were ready to work as field researchers. In the situation of building networks in schools, those core teachers worked as mentors for their colleagues. The other involved parties agreed to carry out their tasks. The core teachers' team interviewed and recorded the opinions and practices of the other members in their individual networks.

2.5.3 The research team worked closely with a core team to conduct needs assessment related to HL. The needs assessment was conducted by conducting a meeting of all stakeholders; school administrators, mayor of the city and his deputy, head of municipality public health office; public health personnel under the Ministry of Health, professional nurses, and three core teachers. The findings from the meeting were analyzed and summarized for the key agenda.

2.5.4 The identification of needs in school was conducted. The findings were analyzed and summarized then listed in the agenda along with the needs assessment from the stakeholders meeting. All data from the needs assessment was analyzed by gap analysis.

Table 2. Identification of needs in school

\begin{tabular}{lll}
\hline \multicolumn{1}{c}{ List of problems } & \multicolumn{1}{c}{ Development strategies } & \multicolumn{1}{c}{ Expected outcome } \\
\hline - Poor health & $\bullet$ HL promotion & $\bullet$ Better health \\
- No exercise & $\bullet$ Classroom based activities & $\bullet$ Healthy nutrition \\
- Diabetes & School and community activities & $\bullet$ Understanding and awareness of \\
- Malnutrition & $\bullet$ Community network & sexual behavior \\
- Premature sex & & - School and community \\
- School age pregnancy & collaboration \\
- Unsafe sex & $\bullet$ Students and families increase \\
- Drug involvement & HL outcomes - functional, \\
& interactive, and communicative \\
\hline
\end{tabular}

2.5.5 Project implementation based on networking. Focus group discussions were conducted for outlining development strategies among key parties such as school administrators, core teachers, deputy mayor, head of public health personnel, representative of parents, and research team.

\subsubsection{The Teachers' Network}

The teacher's network was a procedure network. Teachers developed school activities and learning units in mathematics, science, and Thai language for promoting HL. Teachers were trained to develop activities and teaching strategies based the HL approach. This approach includes access, understanding, assessment, and utilization and communication stages. The access stage requires that teaching and activities should provide students with the knowledge to get to the root of problems or issues. The understanding stage requires teaching and activities that allow students to understand the problems and also to gain subject knowledge in order to find the possible solutions. The assessment stage gives students a chance to validate their knowledge and solutions 
for those problems or issues. The utilization stage allows students to apply their knowledge and ideas related to issues. The communication stage gives a chance for students to communicate their knowledge of health issues to their community. After training, teachers launched HL school activities and learning units. The monitoring and evaluation activities were conducted every three months. The training sessions and participatory work plans were also conducted.

\subsubsection{The Stakeholders' Network}

The stake holders' network was considered as a strategic network. This was because teachers and researchers alone cannot run the HL as effectively and sustainably without the involvement of the community.

\subsection{Data Analysis}

The obtained qualitative data was analyzed by content analysis.

Table 3. Framework of content analysis

\begin{tabular}{ll}
\hline Data Source & Roles and effectiveness of project implementation \\
\hline School teachers' network & - Instructional template Developed by teachers, After Action Reflect \\
Students & - Opinion, understanding and knowledge about HL; assessed by teachers' \\
& observation and students' profile \\
Parents and Community & - interviewed by core teachers \\
Organizations & - field note from meeting and focus group discussion and After Action Reflect \\
\hline
\end{tabular}

\section{Findings and Discussion}

In the school network in Promoting HL, students held three levels of HL: functional, interactive, and communicative. The educational sharing network was established among the research team from the university, municipality office, and school teachers. Policy implementation strategies were also formed. These issues are discussed.

\subsection{Students' Improvement in Levels of HL}

Based on the teachers' reports, students showed improvement in HL. The teachers developed their teaching template using the HL approach; access, understanding, assessment, utilization, and communication. The teachers' field notes records revealed that most of students understood HL and showed a behavioral change in their practices. The students also transferred their knowledge and experiences gained from HL to their parents.

Important evidence could be observed in the practices of students of a healthier dietary pattern. These practices included asking parents to prepare their breakfast instead of skipping it. The parents also reported to the teachers about the attitude changes in their children eating habits. This may be because the well-planned lesson planed based on HL approach. In the lesson plans students learned to acquire information, enter the cognitive development process, consider the choices with critical thinking, practices, evaluation such practices and distribute such knowledge gained to others. The parents told the teachers that their children were so interested in what they learned about healthy eating and practices. Some of them even told their parents to stop smoking or to buy more fruits and fewer sweets. The changing eating habits among students also had an impact on the pushcarts selling soft drinks in front of school. These pushcarts had to change their types of food and drinks because students declined to consume the unhealthy food, candy or soft drinks. This indicates that students continuously gained HL from functional and interactive to communicative HL.

With the development of teaching strategies, students enjoyed their lessons more than in the past. During the two years of the project, the students seemed to develop not only their thinking skills but also improved their learning performance. Rosenthal (2013, p. 4) reported that "Healthy eating habits are a key ingredient to student academic success." It seems that the network could lay a foundation for critical and constructive citizens concerning health issues.

\subsection{Establishing of Educational Sharing Network}

The educational sharing network was established among the research team from the university, the municipality office, and the school teachers. The community network was also established among participating organizations, parents, and schools. It was observed that all stakeholders showed an interest in and understanding of HL. For example, students formed a massage group and learned to screen the type of drinks consumed. 
In the past the Ministry of Public Health was the sole agent in implementing health programmes in schools. They always has to reintroduce the allocation whenever they started their budget year. But the network of all stakeholders drew attention to the importance of HL. Now people see the importance of health in school. This seems to agree with Rosenthal (2013), who pointed out that schools are responsible for the children's entire well-being and not just their academic success.

\subsection{Formed in Policy Implementation Strategies}

The lessons learned from the implementation of HL based on educational sharing network showed that when the research team worked closely with school teachers, through the coordination with the community network, and through the coordination of core teachers, the project could run smoothly. This may be because the core teachers were empowered from the research team. The research team provided significant information, worked along with core teachers, monitored teachers' lesson plan development, provided support to core teachers to attend important meetings, and gave them special privileges in direct contact to research team. Roppaport (1981 cited in Perkins, 1995) pointed out that empowerment is a construct that links individual strengths and competencies. Page and Czuba (1999) concluded that empowerment is a mutual process where it opens to participants the recognition of their values and beliefs. It is a process that helps them gain control over their own lives. In this present study, the teachers felt confidence after they were empowered. They were motivated to try the new instructional approach of HL. They collaborated with colleagues and supported each other. As for networking with community, the programme engaged parents and community organizations in HL efforts.

\subsection{Strategies for Policy Implementation}

From the implementation of HL in Sri Muang Phen municipal school, it was found that: 1) schools can provide health knowledge and information for students and parents as well as a center for networking development, and

2) The Municipality Office is a key organization for maintaining collaborative work among all involved parties. This means that the Municipality Office has to set up work plans and provide continuous project support of the HL effort.

\section{Acknowledgments}

This research was financial supported by the Foundation of Health Promotion, Thailand.

\section{References}

Healthy People. (2010). Objectives 11-12 improvement of HL, community health: Priorities and strategies for progress, action plans to achieve the health community objective. In U.S. Department of Health and Human Services. Washington: U.S. Government Printing Office. Retrieved from http://odphp.osophs.dhhs.gor/ project/healthcomm/objective.htm

Institute of Medicine. (2004). Health literacy a prescription to end confusion. Washington, D.C: The National Academic Press.

Ma-Oon, R. (2009). The effectiveness of the model on health promotion behaviors and diseases prevention for middle schools students. (Unpublished research report). Kasertsart University, Bangkok, Thailand.

Mark, E., Hudson, N., Deal, T. M., Pateman, B., \& Middleton, K. (2007). Promoting health literacy through the health education assessment project. Journal of School Health, 77(4), 157-163. http://dx.doi.org/10.1111/j.1746-1561.2007.00186.x

Nutbeam, D. (1998). Health promotion glossary. Health Promotion International, 13, 349-364. http://dx.doi.org/10.1093/heapro/13.4.349

Nutbeam, D. (2000). Health literacy as a public goal: A challenge for contemporary health education and communication strategies into $21^{\text {st }}$ century. Health Promotion International, 15(3), 259-267. http://dx.doi.org/10.1093/heapro/15.3.259

Nutbeam, D. (2008). The evolving concept of health literacy. Social Science \& Medicine, 67, 2072-2078. http://dx.doi.org/10.1016/j.socscimed.2008.09.050

Page, N., \& Czuba, C. E. (1999). Empowerment: What is it? Journal of Extension, 37(5). Retrieved from http://www.joe.org/joe/1999october/comm1.php

Parker, R. M., Ratzan, S. C., \& Nicole, L. (2003). Health literacy: A policy challenge for advancing high-quality health care. Health Affairs, 22(4), 147-153. http://dx.doi.org/10.1377/hlthaff.22.4.147

Peerson, A., \& Saunders, M. (2009). Health literacy revisited: what do we mean and why does it matter? Health Promotion International, 24(3), 285-296. http://dx.doi.org/10.1093/heapro/dap014 
Perkins, D. D. (1995). Empowerment theory, research and application. American Journal of Community Psychology, 23(5), 569-579. http://dx.doi.org/10.1007/BF02506982

Rosenthal, L. (2013). Healthy students, heathy schools: New initiatives focus on students' well being. Harvard Education Letter, 29(6), 1-8.

St. Leger, L., \& Nutbeam, D. (2000). A model for mapping linkages between health and education agencies to improve school health. Journal of School Health, 70, 45-50.

St. Leger, L. (2001). School health literacy and public health: Possibilities and challenges. Health Promotion International, 16(2), 197-205. http://dx.doi.org/10.1093/heapro/16.2.197

World Health Organization. (1998). Health Promotion Glossary. Retrieved from http://www.who.int/ healthpromotion/about/HPR\%20Glossary\%201998.pdf?ua=1

\section{Copyrights}

Copyright for this article is retained by the author(s), with first publication rights granted to the journal.

This is an open-access article distributed under the terms and conditions of the Creative Commons Attribution license (http://creativecommons.org/licenses/by/3.0/). 